\title{
THE P WAVE IN THE ELECTROCARDIOGRAM IN THE DIAGNOSIS OF HEART DISEASE
}

\author{
BY \\ PAUL THOMAS* AND DAVID DEJONG $\dagger$ \\ From the Cardiac Department of the London Hospital
}

Received November 17, 1953

Since Einthoven designated the first positive wave of the electrocardiogram the $\mathrm{P}$ wave, there have been many papers that discuss its various aspects. Early interest was directed more to its behaviour in arrhythmia and to its use for measuring disturbances of conduction. With further knowledge of electrocardiography, interest changed from the atrial tracing to the more obvious ventricular tracing. In recent years, however, with the introduction of surgery for the relief of certain congenital and acquired cardiac lesions, and the advent of newer methods in diagnosis, interest has once again turned to the rather neglected atria and methods for detecting their normal function and disturbances.

With the development of electrocardiography, standards of recording improved within the scope of the technical limitations of the apparatus, and since the ventricular tracing was more important, standardization of voltage and paper-speed most suitable for an acceptable QRS tracing was adopted. While these established criteria allowed a regular recording of the $\mathbf{P}$ wave, it was not expected to be anything more than a relatively simple convex positive wave. Though irregularities were noted and associated empirically with cardiac lesions such as mitral stenosis, there was no clear understanding of the nature and mechanism of the atrial activation process and its relation to the $P$ wave. Recently, following the use of more sensitive means of recording, better frequency response, faster paper-speed, and intra-cavity, œsophageal, and epicardial leads, the true nature of the atrial wave has been delineated.

This more accurate recording of the atrial activity has been done in both animals and man using different methods, and all have produced a fairly consistent tracing (Kisch, et al. 1947; Hecht and Woodbury, 1950; Oblath and Karpman, 1951; Endelberg, 1951; Wenger and Hofmann-Credner, 1952). It has shown a diphasic tracing (plus-minus) with a marked intrinsic deflection. Such a tracing is considered to represent the electrical activity in one atrium. It has also been shown that the two atria are asynchronous in their contraction (Fredericq, 1906; Bachmann, 1916; Levine et al., 1949). Using œsophageal leads to record left atrial activity, and epicardial or intra-cavity leads for right atrial activity, it was found that while the pattern in both was similar the left atrial pattern followed that of the right at an interval of 0.03 to 0.04 second (Groedel and Borchardt, 1948; Wenger and Hofman-Credner, 1952; Reynolds, 1953). A comparison of $\mathbf{P}$ waves in direct leads with those in standard limb and chest leads by Hecht and Woodbury (1950) revealed a similar though less pure pattern in the latter, depending upon the distance the electrode was from the atria. They also demonstrated that the first part of the $P$ wave is derived from right atrial activity, and the second part from left atrial activity, both in health and disease.

In the standard electrocardiogram, because of the distance of the electrode from the atria,

* Present address: Sacramento Medical Clinic, Sacramento, California.

$\dagger$ Present address: Montreal General Hospital, Montreal, Canada. 
lesser sensitivity, and slower paper-speed, the details seen in direct recordings become blunted, but some details of both the intrinsic deflection and of separate atrial activity due to asynchronization can usually be detected in the normal tracing if carefully observed. It is the purpose of this paper to record the measurements and contours of $\mathbf{P}$ waves in standard limb and chest leads in health and in heart disease to see if a better understanding of right and left atrial activity could be noted for use in clinical electrocardiography.

\section{Method AND MATERIAL}

A total of 345 normal and abnormal cases were selected on a clinical basis according to the criteria listed below. The $P$ waves were measured and carefully analysed with special attention given to their configuration. No record showing evidence of abnormal rhythm, rate, or conduction was selected as it was desired to exclude their direct or indirect effects on the $\mathbf{P}$ wave. All records were taken by a Cambridge string-galvanometer electrocardiograph with photographic recording and were devoid of muscle tremor.

The machine was standardized so that a current of 1 millivolt produced a deflection of $1 \mathrm{~cm}$., and major time markings were $0.20 \mathrm{sec}$. apart. The leads taken included the standard limb leads I, II, III, with IIIR (lead III in deep inspiration) and the chest leads CR1, CR4, and CR7.

There were 100 healthy adults (63 men and 37 women) selected from cases sent to the cardiac department for routine examination. A history, clinical examination, and cardioscopy were performed on each patient and heart disease and common diseases that might affect the heart were excluded. There were 71 cases of pure mitral stenosis who showed mid-diastolic and presystolic murmurs, a relatively small heart, and an enlarged left atrium on cardioscopy. They were subdivided as follows: asymptomatic or minor symptoms, 24 cases; moderately incapacitated with breathlessness, 23 cases; severely incapacitated, 24 cases. Also there were included 10 cases that had, in addition to mid-diastolic and pre-systolic murmurs and an enlarged left atrium, generalized cardiac enlargement, and associated lesions such as considerable mitral incompetence or aortic incompetence. In the selection of cases for this group, it was found that a large number, especially those with giant left atria, had atrial fibrillation and could not be assessed for $P$ wave activity. Cases of hypertension were studied and 61 were selected and belonged to the following groups: raised blood pressure without evidence of cardiac enlargement, 25 cases; hypertension with definite evidence of left ventricular enlargement, 24 cases; hypertensive heart failure, 12 cases. To be included in any group the minimal level of blood pressure was 180 systolic and 110 diastolic. There were 39 cases of pulmonary disease divided as follows: marked emphysema causing respiratory distress, but not showing heart failure, 24 cases; emphysema with heart failure, 11 cases; primary pulmonary hypertension, 4 cases. Fifty cases of congenital heart disease were selected and divided as follows: pulmonary stenosis, 10 cases; atrial septal defect, 13 cases; ventricular septal defect, 15 cases; patent ductus arteriosus, 12 cases: in those cases in which a diagnosis was not obvious from examination and other clinical studies, catheterization had been carried out to help correct interpretation. Thirteen cases of constrictive pericarditis were included.

It was the purpose of this investigation to study standard limb and chest lead electrocardiograms in both healthy patients and those with heart disease, and to compare this information with that received from direct recordings. From this we hoped to gain a truer understanding of the meaning of the different shape of $\mathbf{P}$ waves, as well as test the evidence for separate atrial activity in the standard electrocardiogram. Since diphasic and pointed waves resemble the direct and œsophageal recordings, slightly modified by the distance of the electrode from the atria, it was felt that these waves represent activity of one atrium. Also because of asynchronization of atrial response, the bifid wave was regarded as giving the truest representation of bi-atrial activity. We therefore analyzed the $\mathrm{P}$ waves for configuration noting in which lead each type occurred most commonly, and in the case of bifid waves, which peak was the more prominent. We later correlated this information with the various disease groups in which the strain on the individual atrium was 
Bifid

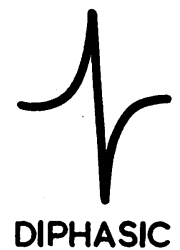

DIPHASIC

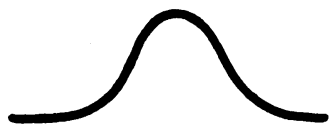

CONVEX

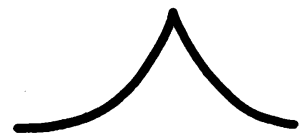

POINTED

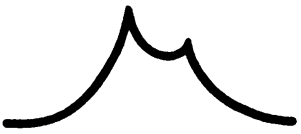

FIRST PEAK

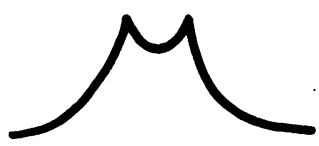

EQUAL

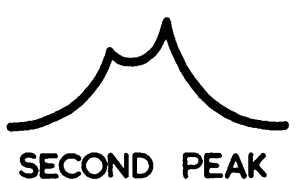

Impure Bifid

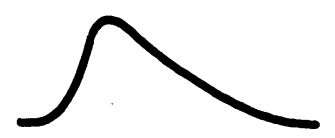

SLANTING DOWNSTROKE
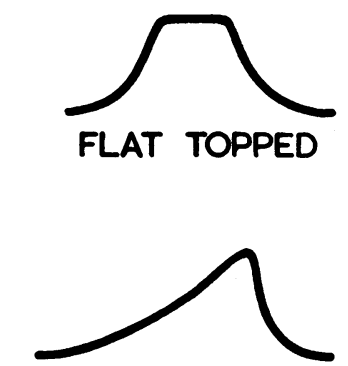

SLANTING UPSTROKE

FIG. 1.-P wave configuration found in health and in heart disease.

known, to test the presence of single or combined atrial involvement. Four major types of deformity were found, namely: bifid, diphasic, pointed, and convex (Fig. 1 and 2). Three types of bifid waves were recognized: first peak type, where the first peak was higher; equal peaks type, where both peaks were equal; and second peak type, where the second peak was higher. Hereafter, bifid waves will be referred to by these types. The duration between peaks for every bifid wave was also recorded. This measurement is referred to as the peak interval. A further group of blunted waves was also seen and classed as: slanting downstroke (similar to first peak type), flat-topped (similar to equal peaks type), and slanting upstroke (similar to second peak type). This blunted or impure group of bifid waves was less common and so listed after the pure and more common group.

The second main type of wave was the diphasic deflection resembling the true intrinsic deflection seen with direct recording. (A possible variation of this, a diphasic (minus-plus) deflection, was considered initially, but was excluded after it was found that it did not occur in our series.) Next, a pointed wave was recognized, being one with only one point to its apex and with no negative component. It was felt that the pointed wave, especially when narrow, represented activity of one atrium, and when wider, represented both atrial waves superimposed, but with one of them predominant. The simple convex type was next examined, and considered to be a reflection in blunted form of the equal peaks type of bifid wave. Though the convex wave was less pure than the other main types it was very common and thus included as a major group.

The last two varieties considered were isoelectric and negative. The former was considered present when a perfectly smooth baseline was uninterrupted in that lead where the $P$ wave would be expected, and with the presence of $\mathbf{P}$ waves in other leads which, though not synchronously recorded, would practically rule out the possibility of sino-atrial block. A negative deflection was taken as one whose excursion extended only below the baseline and could be of any configuration.

The $P$ waves were studied for height (to the nearest $0.5 \mathrm{~mm}$.) and duration (to the nearest $0.01 \mathrm{sec}$.). The top of the T-P segment was used as the base line for measurements of height. The internal distance of the $\mathbf{P}$ wave on an extension of the bottom of this line was used for measurements of duration. 

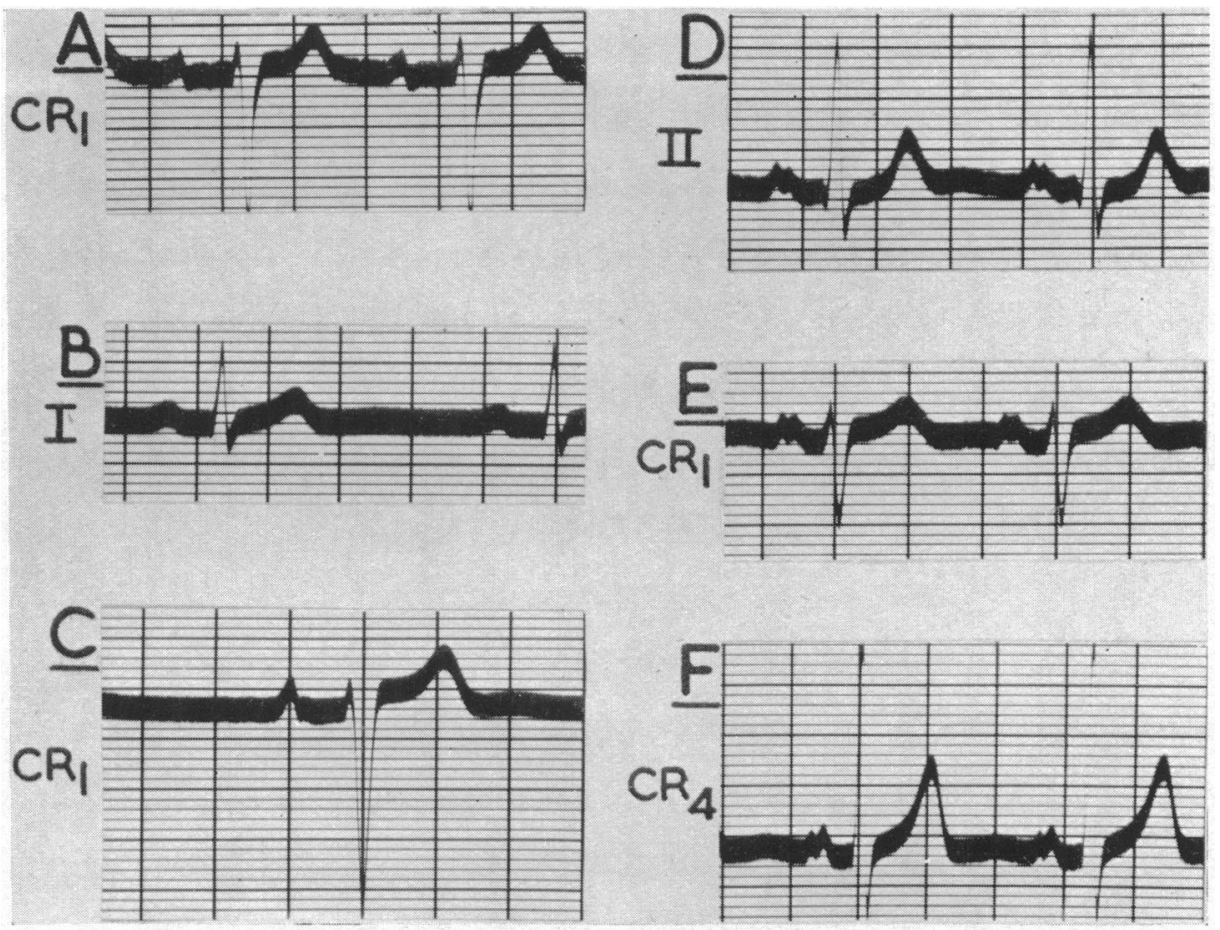

FIG. 2.-Examples of $P$ wave configuration found in health; A Diphasic; B Convex; C Pointed; D First peak type of bifidity; E Equal peaks bifidity; F Second peak bifidity.

The misinterpretation of a $U$ wave for the sharp first peak of a bifid wave was not a problem. Nor was it a problem with the $\mathrm{T}$ wave, since all records studied had a normal rate and $\mathrm{P}-\mathrm{R}$ interval. We did not find the Ta wave to be of significance in our series.

After a standard of normal had been set up from our series and from data previously published, the records in the disease groups were re-studied. The incidence of the types of abnormal waves found in the various leads as well as their correlation with the disease patterns was analysed. From this information, criteria were established for evidence of right, left, and combined atrial abnormality.

\section{RESULTS}

In Health. Of all $\mathrm{P}$ waves recorded in this group, 49 per cent were convex in shape, 23 per cent were pointed, and 15 per cent bifid. These latter figures are in general agreement with Leatham (1950) who used CR leads and found bifid waves in 17 per cent. Using only limb leads Lewis (1912) found 30 per cent, White et al. (1944) 35 per cent, and Graybiel (1944) 28 per cent. In addition, we found a small scattering of other varieties, including 4 per cent diphasic, 2 per cent negative, and 7 per cent bifid waves which were impure.

A bifid wave was present in one or more leads in 82 per cent of normal electrocardiograms. It tended to occur in two or more leads, but appeared most commonly in lead CR4. The first peak type of wave was most common in CR1, 47 per cent, and in CR4, 30 per cent, while it never occurred in CR7. Waves with equal peaks occurred most frequently in chest leads; CR4, 27 per cent; CR1, 19 per cent; CR7, 15 per cent. Second peak type waves were found most frequently in CR4, 33 per cent; CR7 had 19 per cent; there were none in CR1. The $\mathbf{P}$ waves in CR1 were most commonly first peak type or pointed, with a diphasic type 
of deflection in 4 per cent, but never negative. The waves in CR4 were usually bifid of all types, or convex, but never diphasic. CR7 showed most commonly a second peak type, pointed, or convex, but never first peak type or diphasic. Chest leads were best to display bifid waves, and since first peak type and diphasic waves occurred exclusively in right chest leads and second peak type exclusively in left chest leads, they were also the best places for the study of single or bi-atrial activity. In all these normal $\mathbf{P}$ waves the bifid variety was best and most frequently seen in CR4, which showed 52 per cent of all bifid waves. The tallest P wave was most frequently and best seen in lead II, 49 per cent; and next in CR4, 28 per cent. The average interval between peaks in all bifid $P$ waves was $0.036 \mathrm{sec}$., with a range of $0.02-0.04$, and never longer than $0.04 \mathrm{sec}$. This is in agreement with a previous report (Lepeschkin, 1951). The interval was longest in CR4.

In leads I and II the P wave was most commonly convex or pointed and never negative. Both III and IIIR showed convex, diphasic, isoelectric, and negative deflections as normal variations. Negative waves occurred most commonly in leads III and IIIR.

The average height of the $P$ wave for all leads was $1.3 \mathrm{~mm}$., ranging from 0.0 to $3.0 \mathrm{~mm}$. Most were under $2.5 \mathrm{~mm}$. There were only 1.7 per cent that were over $2.5 \mathrm{~mm}$. This is in agreement with other authors (Sorsky and Wood, 1937; Wood and Selzer, 1939; Deeds and Barnes, 1940; Wilson, 1943; White et al. 1944; Graybiel et al., 1944; and Leatham, 1950). We found the maximum height in lead I to be $2.0 \mathrm{~mm}$., in lead CR1, $2.5 \mathrm{~mm}$., and in leads II, III, IIIR, CR4, and CR7 to be $3.0 \mathrm{~mm}$.

The average duration of the $P$ wave for all leads was $0.063 \mathrm{sec}$, with a range of $0.03-0.10 \mathrm{sec}$., and with no significant variation in the various leads. Most authors agree with this (Sorsky and Wood, 1937; White et al., 1944; and Stewart and Manning, 1944). Some (Shipley and Hallaran, 1936; Ashman and Hull, 1937; and Graybiel et al., 1944) found a slightly higher maximum, above $0 \cdot 10 \mathrm{sec}$., in a small number $(2.7 \%, 1 \%$, and $2.4 \%$ respectively). We found in health that no $\mathrm{P}$ wave in any lead was ever more than $3.0 \mathrm{~mm}$. high, $0.10 \mathrm{sec}$. in duration or, when bifid, more than $0.04 \mathrm{sec}$. between peaks.

Mitral Stenosis. In the mitral stenosis group with a small heart and minimal symptoms, 12 of the 24 cases showed abnormal $P$ waves. All of these showed a second peak type wave in CR7 (Table I). In CR4 there were 10 abnormal waves; these were mostly equal or second peak in type. Two cases showed, in addition, abnormally pointed waves in CR1. There was also an increase in the average peak interval, $0.06 \mathrm{sec}$., with a range of $0.03-0.08 \mathrm{sec}$. In the mitral stenosis group with a small heart and moderate symptoms, the average peak interval was increased to $0.06 \mathrm{sec}$., with a maximum of $0.10 \mathrm{sec}$. The greatest number of bifid waves, as well as the largest average peak interval, occurred in CR4. The average height was increased to $1.9 \mathrm{~mm}$. with a maximum of $8.0 \mathrm{~mm}$. The average duration was increased to $0.082 \mathrm{sec}$. with a maximum of $0.13 \mathrm{sec}$. Nineteen of the 23 cases showed abnormal $P$ waves. In CR7 14 showed second peak type and 3 were of the equal peaks type. In CR4 they were bifid of all types and, in addition, in CR1 there were 3 abnormally pointed, 2 diphasic, and one of first peak type. In the mitral stenosis group with a small heart and severe symptoms there was a larger total of bifid waves, 34 per cent, with an increase in the incidence of the first peak type to 15 per cent. The average peak interval was increased to $0.065 \mathrm{sec}$. Twenty-three of the 24 cases showed abnormal $P$ waves. Of these abnormal waves CR7 showed 14 second peak type, 7 equal peaks type, and one pointed. Lead CR4 showed bifid waves of all types and, in addition, in CR 1 there were 6 pointed and 5 diphasic waves. The mitral stenosis cases with a large heart showed the same general pattern as the above. The total number of bifid waves increased again to 46 per cent and diphasic waves occurred a little more commonly, 12 per cent; most of them in CR1. The average peak interval was $0.062 \mathrm{sec}$. All 10 cases showed abnormal $P$ waves. There were 9 abnormal second peak type waves in CR7. Bifid waves of all varieties occurred in CR4 and, in addition, in CR1 there were 3 pointed and 2 diphasic waves.

Hypertension. There were no abnormalities noted in the groups with and without left ventricular enlargement. In the hypertensive heart failure group, 3 of the 12 cases showed abnormal $P$ waves. In CR7 two were of second peak type and one was of the equal peaks type. One abnormal diphasic wave occurred in CR1.

Pulmonary Disease. There were few significant findings in the two groups of emphysema. The only abnormal waves occurred in the emphysema with failure group and these were in two patients with clinical evidence of pulmonary hypertension who showed abnormal diphasic waves in CR1. There were not enough cases of primary pulmonary hypertension to draw conclusions, but it was interesting to note that all 4 records were abnormal. The average height was increased to $2.3 \mathrm{~mm}$. with a range of $0.5-6.0 \mathrm{~mm}$., the tallest average being $3.9 \mathrm{~mm}$. in lead CR1. The duration of the $P$ waves was normal. There was an increase in pointed waves to 79 per cent (normal 22.6\%). These occurred in all leads almost equally, with especially tall and pointed ones in CR1. Of the 4 abnormal records, 3 were tall pointed waves and 
TABLE I

Incidence of the Specified P Wave Deformity (expressed as Percentage) in the Three Chest Leads in 100 Healthy Subjects and in 245 Patients with Heart Disease

\begin{tabular}{|c|c|c|c|c|c|c|c|c|c|c|c|c|c|c|c|c|}
\hline \multirow{3}{*}{ Clinical state } & \multirow{2}{*}{\multicolumn{3}{|c|}{$\begin{array}{l}\text { Pointed } \\
\text { P waves }\end{array}$}} & \multirow{2}{*}{\multicolumn{3}{|c|}{$\begin{array}{l}\text { Diphasic } \\
\text { P waves }\end{array}$}} & \multicolumn{9}{|c|}{ Bifid P waves } & \multirow{3}{*}{$\begin{array}{c}\text { Prolonged } \\
\text { peak } \\
\text { interval } \\
\text { (over } \\
0.04 \mathrm{sec} .)\end{array}$} \\
\hline & & & & & & & \multicolumn{3}{|c|}{$\begin{array}{c}\text { First peak } \\
\text { type }\end{array}$} & \multicolumn{3}{|c|}{$\begin{array}{c}\text { Equal peaks } \\
\text { type }\end{array}$} & \multicolumn{3}{|c|}{$\begin{array}{c}\text { Second peak } \\
\text { type }\end{array}$} & \\
\hline & CR1 & CR4 & CR7 & CR1 & CR4 & CR7 & CR1 & CR4 & CR7 & CR 1 & CR4 & CR7 & CR 1 & CR4 & 4R7 & \\
\hline $\begin{array}{lll}\text { In health } & \ldots & \ldots\end{array}$ & 0 & 0 & 0 & $\mathbf{0}$ & 0 & 0 & 0 & 0 & $\mathbf{0}$ & 0 & 0 & 0 & 0 & 0 & 0 & 0 \\
\hline $\begin{array}{l}\text { Mitral stenosis: } \\
\text { Pure-- } \\
\text { Mild symptoms } \\
\text { Moderate symptoms ... } \\
\text { Severe symptoms } \ldots \\
\text { Great heart enlargement }\end{array}$ & $\begin{array}{r}8 \\
12 \\
24 \\
30\end{array}$ & $\begin{array}{l}4 \\
0 \\
4 \\
0\end{array}$ & $\begin{array}{l}\mathbf{0} \\
0 \\
0 \\
0\end{array}$ & $\begin{array}{r}0 \\
8 \\
20 \\
20\end{array}$ & $\begin{array}{l}\mathbf{0} \\
\mathbf{0} \\
\mathbf{0} \\
\mathbf{0}\end{array}$ & $\begin{array}{l}0 \\
0 \\
0 \\
0\end{array}$ & $\begin{array}{l}0 \\
4 \\
0 \\
0\end{array}$ & $\begin{array}{r}4 \\
17 \\
17 \\
20\end{array}$ & $\begin{array}{l}\mathbf{0} \\
\mathbf{0} \\
\mathbf{0} \\
\mathbf{0}\end{array}$ & $\begin{array}{l}0 \\
0 \\
0 \\
0\end{array}$ & \begin{tabular}{r|}
20 \\
12 \\
25 \\
8
\end{tabular} & $\begin{array}{r}0 \\
13 \\
29 \\
0\end{array}$ & $\begin{array}{l}\mathbf{0} \\
\mathbf{0} \\
\mathbf{0} \\
\mathbf{0}\end{array}$ & $\begin{array}{r}17 \\
26 \\
29 \\
0\end{array}$ & $\begin{array}{l}46 \\
61 \\
60 \\
90\end{array}$ & $\begin{array}{r}50 \\
83 \\
96 \\
100\end{array}$ \\
\hline $\begin{array}{l}\text { Hypertension: } \\
\text { Without heart enlargement } \\
\text { With heart enlargement } \\
\text { With heart failure }\end{array}$ & $\begin{array}{l}\mathbf{0} \\
\mathbf{0} \\
\mathbf{0}\end{array}$ & $\begin{array}{l}\mathbf{0} \\
\mathbf{0} \\
\mathbf{0}\end{array}$ & $\begin{array}{l}\mathbf{0} \\
\mathbf{0} \\
\mathbf{0}\end{array}$ & $\begin{array}{l}\mathbf{0} \\
\mathbf{0} \\
\mathbf{0}\end{array}$ & $\begin{array}{l}\mathbf{0} \\
0 \\
0\end{array}$ & $\begin{array}{l}\mathbf{0} \\
\mathbf{0} \\
\mathbf{0}\end{array}$ & $\begin{array}{l}0 \\
0 \\
0\end{array}$ & $\begin{array}{l}0 \\
0 \\
0\end{array}$ & $\begin{array}{l}0 \\
0 \\
0\end{array}$ & $\begin{array}{l}0 \\
0 \\
0\end{array}$ & $\begin{array}{l}\mathbf{0} \\
\mathbf{0} \\
\mathbf{0}\end{array}$ & $\begin{array}{l}0 \\
0 \\
8\end{array}$ & $\begin{array}{l}0 \\
0 \\
0\end{array}$ & $\begin{array}{l}0 \\
0 \\
0\end{array}$ & $\begin{array}{r}0 \\
0 \\
16\end{array}$ & $\begin{array}{r}0 \\
0 \\
24\end{array}$ \\
\hline Emphysema only .. & 0 & 0 & 0 & 0 & 0 & $\mathbf{0}$ & 0 & 0 & 0 & 0 & 0 & 0 & 0 & 0 & 0 & 0 \\
\hline Emphysema; heart failure & 0 & $\mathbf{0}$ & 0 & 18 & 0 & 0 & 0 & 0 & 0 & 0 & $\mathbf{0}$ & $\mathbf{0}$ & 0 & 0 & $\mathbf{0}$ & $\mathbf{0}$ \\
\hline $\begin{array}{c}\text { Primary pulmonary hyper- } \\
\text { tension } \ldots\end{array}$ & 75 & 50 & 25 & 25 & 0 & 0 & 0 & 0 & 0 & 0 & 0 & $\mathbf{0}$ & 0 & 0 & 0 & 0 \\
\hline Pulmonary stenosis & 50 & 30 & 10 & 0 & 0 & 0 & 20 & $\mathbf{0}$ & 0 & 0 & 0 & 0 & 0 & 0 & 0 & 0 \\
\hline Atrial septal defect & 8 & 0 & 0 & 8 & 0 & 0 & 0 & 0 & 0 & $\mathbf{0}$ & 0 & 0 & $\mathbf{0}$ & 0 & 0 & 0 \\
\hline Ventricular septal defect & 7 & 0 & 0 & $\mathbf{0}$ & 0 & 0 & 0 & 0 & 0 & 0 & $\overline{0}$ & $\overline{0}$ & 0 & 0 & 0 & 0 \\
\hline Patent ductus arteriosus & 0 & 0 & 0 & 0 & 0 & 0 & 0 & 0 & 0 & 0 & 0 & 0 & 0 & 0 & 0 & 0 \\
\hline Constrictive pericarditis & 0 & 0 & 0 & 0 & 0 & 0 & 21 & 7 & 0 & 0 & 64 & 14 & 0 & 7 & 56 & 85 \\
\hline
\end{tabular}

one was diphasic in CR1. There were two abnormally pointed waves in CR4 and one in CR7, but of lower voltage than in $\mathrm{CR} 1$.

Congenital Heart Disease. In pulmonary stenosis there was an increase in the average height of the $\mathbf{P}$ wave from the normal of 1.3 to $2.1 \mathrm{~mm}$., the highest average occurring in CR4. The range was 0.5 $5.0 \mathrm{~mm}$. There was an increase in the number of pointed waves $(50 \%)$ occurring fairly frequently in all leads, but most commonly in CR1. Seven of the 10 cases showed abnormal $P$ waves. Of these, 5 were tall and pointed in CR1, and 2 were of the first peak type. There were three abnormally pointed waves in CR4 and one in CR7, but of lower voltage than those in CR1. In atrial septal defect the peak interval was increased, the average being $0.054 \mathrm{sec}$., with a range of 0.03-0.07 sec. Two of 13 cases showed abnormal $P$ waves; one being pointed and one diphasic in CR1. In ventricular septal defect, one among 15 was abnormal; this was a tall pointed wave in CR1. No abnormal P waves were found in the patients with patent ductus arteriosus.

Constrictive Pericarditis. There was a definite increase in the number of bifid waves $(40.5 \%)$. There were 19 per cent of the second peak type, which were most common in leads II and CR7. The average peak interval was increased to $0.061 \mathrm{sec}$., with a range of 0.03-0.09 sec. Eleven of the 13 showed abnormal $P$ waves. In CR7, eight were of the second peak type and two were of the equal peaks type. In CR4, nine were equal peaks type, one second peak type, and one first peak type. In CR1 three showed tall first peak type waves and also four others that were of normal voltage, but with a long peak interval.

The tallest waves in the series occurred in pulmonary stenosis and moderate and severe mitral stenosis. 
The greatest average duration occurred in moderate and severe mitral stenosis as well as in those cases of mitral stenosis with large hearts. The average $P$ wave duration was not significantly increased in the other cases in the series. Bifid $\mathbf{P}$ waves occurred most commonly in cases with mitral stenosis and large hearts $(45 \%)$ and in constrictive pericarditis $(40.5 \%)$.

The first peak type wave was seen almost exclusively in CR1 and CR4. The second peak type was seen most commonly in lead CR4 and often in CR7 and II. A prolonged peak interval (greater than $0.04 \mathrm{sec}$.) was found in all abnormal records of cases showing abnormality of the left atrium. This occurred in all abnormal records of mitral stenosis, hypertension with heart failure, and constrictive pericarditis (Table I). The peak interval was normal in all cases showing strain on the right atrium; namely, emphysema, pulmonary hypertension, and pulmonary stenosis.

The incidence of pointed waves was highest in pulmonary hypertension $(79 \%)$ and next highest in pulmonary stenosis $(50 \%)$. There was no significant correlation between the incidence of convex, impure bifid, isoelectric, or negative waves in the various disease patterns.

Lead CR4 was found to show by far the highest incidence of bifid P waves and longest peak intervals, and leads II and CR4 showed the highest incidence of the tallest wave in all leads.

In each disease group the abnormal waves in CR1 were either first peak type, pointed, or diphasic (Table I). No abnormal equal or second peak type waves occurred in this lead. In CR4 the abnormal waves were almost entirely bifid of all types with some abnormally pointed waves. There were no diphasic waves in this lead. In CR7 all abnormal waves were either second peak type, equal peaks type, or pointed. There were no first peak type or diphasic waves in this lead. There were no abnormal convex or negative waves in any of the chest leads. Though some abnormal waves of most types occurred in the limb leads they were less pure, occurred with less frequency, or were absent unless in the chest leads.

In pulmonary stenosis and pulmonary hypertension where the strain was known to be on the right atrium the $P$ waves were most abnormal in CR1, where they were of high voltage and either pointed, first peak type, or diphasic.

In mild to moderate mitral stenosis where the strain is known to be on the left atrium the $\mathbf{P}$ waves were most abnormal in CR7 and CR4, where they were usually abnormally tall second peak type and characteristically with a long peak interval. Less commonly they showed equal peaks type with a normal voltage but a markedly prolonged peak interval.

In some of the severe mitral stenosis cases with pulmonary hypertension or with cardiac enlargement there occurred, in addition to the findings of left atrial abnormality as described above, waves of high voltage either pointed, first peak type, or diphasic in CR1, giving evidence of abnormality of the right atrium as well.

\section{Discussion}

Keeping in mind the true $\mathrm{P}$ wave pattern as found in epicardial leads, and seeking clearer evidence of separate right and left atrial activity in the standard $\mathbf{P}$ wave, the cases were selected clinically for the presence of single lesions graded according to severity of symptoms, and clinical and radiological signs, in which it would be possible to assess with some accuracy which atrium was feeling the brunt of the disturbance. In tabulating the results it was found that there were no significant facts to be derived from the occurrence of convex, bifid of the impure type, isoelectric, or negative waves, and that limb leads only served to corroborate the more definite findings in the chest leads. However, the occurrence of bifid, diphasic, and pointed waves, especially in the chest leads, showed a definite correlation with the various disease groups. In health the first peak and second peak type of waves occurred exclusively in right and left precordial leads respectively. With abnormality of the right atrium, first peak type and diphasic waves occurred only in right chest leads. With abnormality of the left atrium, second peak and equal peaks type of waves occurred only in left chest leads. A prolonged peak interval (greater than $0.04 \mathrm{sec}$.) occurred in all cases showing abnormality of the left atrium and never occurred in cases showing only abnormality of the right atrium. A general, but not always an individual correlation, existed between the size of the atria as found on screening and the size of the $P$ wave.

Hecht and Woodbury (1950) took right direct and intra-atrial and œsophageal leads, as others have done, and found the same pattern of the intrinsicoid deflection. Comparing these with the pattern of $\mathbf{P}$ in V1, he found it similar, though less pure and with a lower voltage due to the distance 
of the electrode from the right atrium. He felt that using $\mathrm{V}$ leads he was unable to diagnose right atrial enlargement. Myers et al. (1947), using V leads, found P waves to be of small amplitude and diphasic or intrinsicoid in 32 per cent in V1. Sorsky and Wood (1937) using CR leads found the $P$ wave to be always positive. Leatham (1950) comparing CR and V leads agreed with this and noted that CR leads gave a higher amplitude and a higher incidence of bifid waves. Thus, it was felt that in this study the use of CR leads gave greater ease of interpretation of right as well as left atrial activity.

By comparing the results of the normal series with the types of $P$ waves found in disease patterns showing strain on one or both atria, criteria were established for the designation of abnormal $\mathbf{P}$ waves showing right, left, and combined atrial abnormality. It was felt that evidence of right atrial abnormality was present when there occurs in CR1 a tall (more than $2.5 \mathrm{~mm}$.) first peak type, diphasic, or pointed $\mathrm{P}$ wave, especially if the latter is found to correspond in time with the first peak of a bifid wave in another lead. Since diphasic waves occurred in our series in only 4 per cent in CR1, any marked increase in their incidence, especially if abnormally tall, was felt to be evidence of right atrial abnormality. Evidence of left atrial abnormality included a tall (more than $3.0 \mathrm{~mm}$.) second peak type wave in CR4 or CR7, and/or an abnormally wide peak interval in a bifid wave in any lead regardless of voltage. An increased peak interval was taken to be evidence of left atrial abnormality since left atrial activation follows that of the right atrium, from which it receives its impulse. Right atrial conduction delay might delay the onset of the $P$ wave as a whole, but it did not seem to affect the interval. Where single broad $P$ waves are found the bi-atrial responses may be regarded as being superimposed, but this seems a function of the vector rather than conduction delay in the right atrium,

Though abnormally pointed waves occurred in a few cases in lead CR7 they were of much lower voltage relatively and when considering the electrocardiogram as a unit, obviously represented a reflection of the taller wave in CR1. This was especially evident when it corresponded in height with the first peak of a bifid wave in another lead. Hecht and Woodbury (1950), using high voltage and a rapid paper-speed, also showed in mitral stenosis that the negative deflection of the intrinsicoid waves in right sternal leads measured out to correspond to the second peak of the bifid wave of left chest leads. We agree with this and show as well that the positive aspect of diphasic waves and tall pointed waves in CR1, when measured from the $Q$ wave, correspond to the first peak of bifid waves in other leads. This aided our evaluation of bi-atrial activity. Evidence of combined atrial abnormality was taken to be any combination of the evidence of right and left abnormality. It was found that the study of the electrocardiogram as a whole, especially the chest leads, gave the best picture of single or bi-atrial activity or abnormality. Using the above criteria, the various disease groups were studied and the incidence of right, left, or combined right and left atrial abnormality were compiled (Table II).

Since numerous diseases cause atrial abnormality and the specific atrium can be diagnosed in the standard electrocardiogram, it is felt that terms such as " $P$ mitrale," and " $P$ pulmonale " used in the past should be replaced by ones denoting the pathological and physiological state similar to those used for ventricular abnormality. Thus the terms right atrial abnormality and left atrial abnormality are suggested and will be used hereafter in this paper whenever the criteria as listed above are met in the diagnosis of right or left atrial abnormality.

Lewis and Gilder (1912) were the first to note an increased incidence of notched $P$ waves in mitral stenosis. Others (Berliner and Master, 1938; Rasmussen and Nyhus, 1948; and Trounce, 1952) have concurred and noted an increase in amplitude and duration as well, calling the pattern "P mitrale." Our results are similar to those of previous authors and, in addition, we note that with an increase in the incidence of total bifid waves (increasing with severity), there occurs an increase of equal and second peak type of bifid waves in CR4 and 7. Asynchronization of atrial activation has been noted by many (Fredericq, 1906; Luisada, 1940; Hecht, 1943; Groedel and Borchardt, 1948; and Levine et al., 1949) and recently especially well by Reynolds (1953) who took direct right and left atrial records during thoracic surgery. Using patients with carcinoma of the 
TABLE II

Incidence of Single and Combined Atrial Abnormaltty (eXpressed as Percentage) in 245 Patients with HEART DISEASE

\begin{tabular}{|c|c|c|c|c|c|c|c|}
\hline Clinical state & $\begin{array}{l}\text { No. of } \\
\text { cases }\end{array}$ & $\begin{array}{c}\text { Single } \\
\text { right } \\
\text { atrial ab- } \\
\text { normality }\end{array}$ & $\begin{array}{c}\text { Single } \\
\text { left } \\
\text { atrial ab- } \\
\text { normality }\end{array}$ & $\begin{array}{l}\text { Combined } \\
\text { atrial ab- } \\
\text { normality }\end{array}$ & $\begin{array}{l}\text { Total } \\
\text { right } \\
\text { atrial ab- } \\
\text { normality }\end{array}$ & $\begin{array}{c}\text { Total } \\
\text { left } \\
\text { atrial ab- } \\
\text { normality }\end{array}$ & $\begin{array}{c}\text { Total } \\
\text { percentage } \\
\text { abnormal }\end{array}$ \\
\hline $\begin{array}{l}\text { Mitral stenosis: } \\
\text { Pure- } \\
\text { Mild symptoms } \\
\text { Moderate symptoms } \\
\text { Severe symptoms .. } \\
\text { Great heart enlargement }\end{array}$ & $\begin{array}{l}24 \\
23 \\
24 \\
10\end{array}$ & $\begin{array}{l}\mathbf{0} \\
0 \\
0 \\
0\end{array}$ & $\begin{array}{l}42 \\
57 \\
50 \\
50\end{array}$ & $\begin{array}{r}8 \\
26 \\
50 \\
50\end{array}$ & $\begin{array}{r}8 \\
26 \\
50 \\
50\end{array}$ & $\begin{array}{r}50 \\
83 \\
100 \\
100\end{array}$ & $\begin{array}{r}50 \\
83 \\
100 \\
100\end{array}$ \\
\hline \begin{tabular}{lclll}
\multicolumn{3}{l}{ Hypertension: } \\
B.P. $\quad$. & $\ldots$ & $\ldots$ & $\ldots$ \\
L.V. & $\ldots$ & $\ldots$ & $\ldots$ & $\ldots$ \\
Heart failure &. & $\ldots$ & $\ldots$
\end{tabular} & $\begin{array}{l}25 \\
24 \\
12\end{array}$ & $\begin{array}{l}0 \\
0 \\
0\end{array}$ & $\begin{array}{r}0 \\
0 \\
25\end{array}$ & $\begin{array}{l}0 \\
0 \\
0\end{array}$ & $\begin{array}{l}0 \\
0 \\
0\end{array}$ & $\begin{array}{r}0 \\
0 \\
25\end{array}$ & $\begin{array}{r}0 \\
0 \\
25\end{array}$ \\
\hline Emphysema only $\ldots \quad \ldots \quad \ldots$ & 24 & 0 & 0 & 0 & 0 & 0 & 0 \\
\hline $\begin{array}{l}\text { Emphysema; heart failure } \\
\text { Primary pulmonary hypertension }\end{array}$ & $\begin{array}{r}11 \\
4\end{array}$ & $\begin{array}{r}18 \\
100\end{array}$ & $\begin{array}{l}\mathbf{0} \\
\mathbf{0}\end{array}$ & $\begin{array}{l}0 \\
0\end{array}$ & $\begin{array}{r}18 \\
100\end{array}$ & $\begin{array}{l}0 \\
0\end{array}$ & $\begin{array}{r}18 \\
100\end{array}$ \\
\hline Pulmonary stenosis & 10 & 70 & 0 & 0 & 70 & 0 & 70 \\
\hline Atrial septal defect & 13 & 15 & 0 & 0 & 15 & 0 & 15 \\
\hline Ventricular septal defect ... & 15 & 7 & 0 & 0 & 7 & 0 & 7 \\
\hline Patent ductus arteriosus .. & 12 & 0 & 0 & 0 & 0 & 0 & 0 \\
\hline Constrictive pericarditis .. & 14 & 0 & 62 & 23 & 23 & 85 & 85 \\
\hline
\end{tabular}

Note the high incidence of right atrial abnormality in pulmonary stenosis and primary pulmonary hypertension, and of left and combined atrial abnormality in mitral stenosis and in constrictive pericarditis.

bronchus as controls, he found the normal asynchronization to be $0.03-0.04 \mathrm{sec}$. This was also true in congenital heart disease studied at operation. In patients with mitral stenosis he found an average of $0.05 \mathrm{sec}$. This is in agreement with the peak intervals of the bifid waves in our series of standard limb and chest lead electrocardiograms; the normal average being $0.036 \mathrm{sec}$. and in mitral stenosis varying from an average of $0.059 \mathrm{sec}$. in mild cases to $0.065 \mathrm{sec}$. in the more severe cases.

In the study of the abnormal P waves in the mitral stenosis groups in our series, it was considered that left atrial abnormality was present in 50 per cent of the cases with mild symptoms, in 83 per cent with moderate symptoms, in 96 per cent with severe symptoms, and in 100 per cent of those with large hearts (Table II). The point of most interest was that, in addition to evidence of left atrial abnormality in a high percentage of cases in all groups of mitral stenosis, there was evidence of associated right atrial abnormality in a third of the cases with moderate symptoms and in half of the more severe cases and those with large hearts. This was most marked in those cases with clinical evidence of pulmonary hypertension (Fig. 3). It is suggested that in a case causing few to moderate symptoms, the atrial record may be normal or show left atrial abnormality. However, if the symptoms are more severe, possibly with pulmonary hypertension, or if general cardiac enlargement occurs, that in addition to a definite left, an associated right atrial abnormality may be evident in the electrocardiogram. Thus it is felt that in mitral stenosis with a bifid wave that has been regarded as abnormal (either increased duration, height, or bifid interval), if the second peak is taller in CR4 and/or CR7, or the bifid interval is prolonged, and in CR1 a normal wave occurs, then the main abnormality lies in the left atrium. However, if the P wave in CR1 is tall, whether 


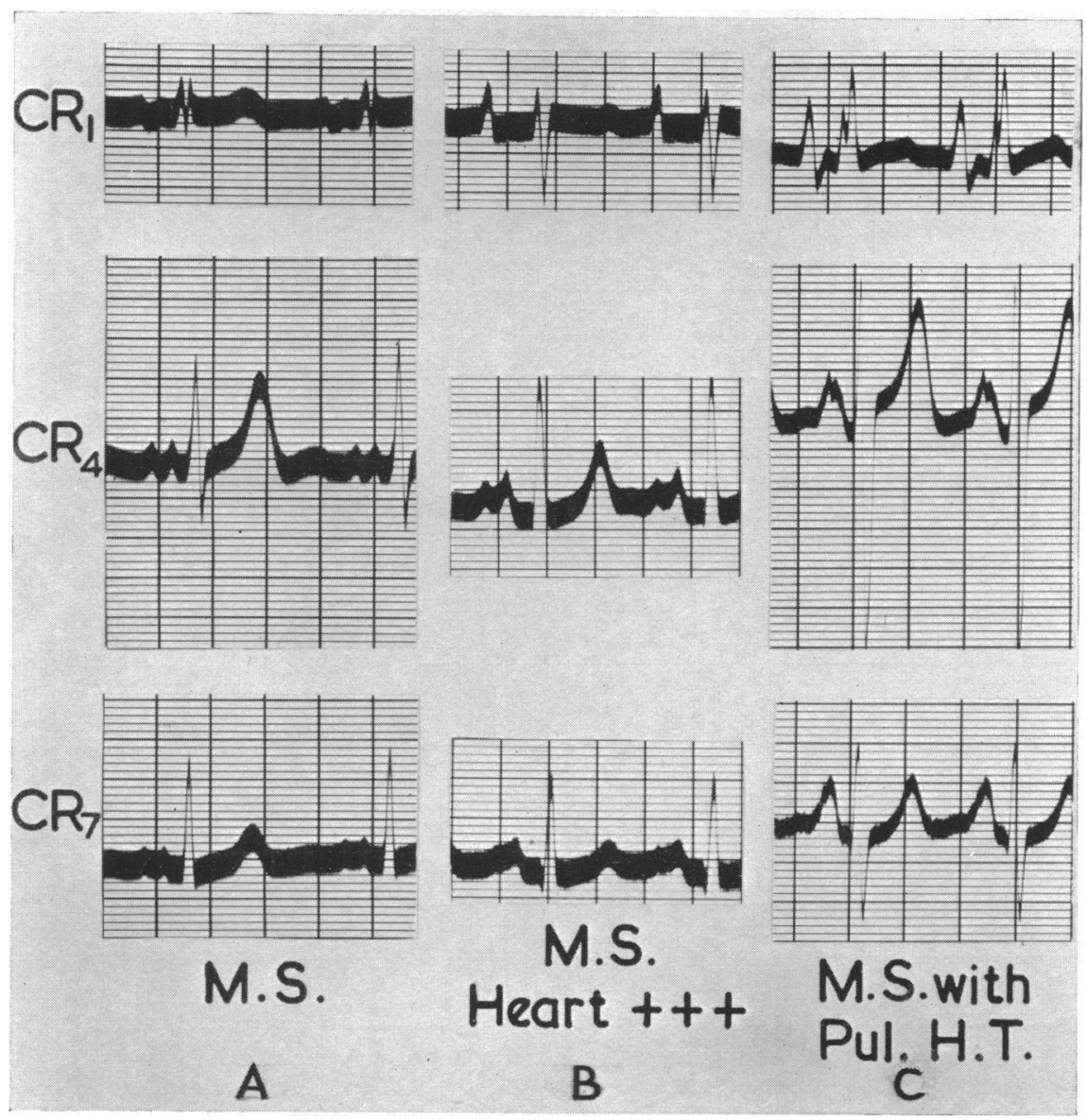

FIG. 3.-Prolonged peak interval in CR4 and 7 in mitral stenosis without cardiac enlargement as evidence of left atrial abnormality $(A)$. Tall pointed and diphasic $P$ waves in CR1 in mitral stenosis with an enlarged heart (B), and in mitral stenosis with pulmonary hypertension (C) showing right atrial abnormality in addition to evidence of left atrial preponderance shown in CR4 and 7.

pointed, diphasic, or first peak type, then the right atrium is also under strain or is enlarged. This, we feel, may be useful in the clinical evaluation of patients with mitral stenosis.

Wood (1939) gave hypertension, in the presence of incipient left ventricular failure and overload of the left atrium, as a cause of increased incidence of bifid waves. We noted a small number of abnormal $P$ waves in those in failure, but the incidence was not sufficient to draw significant conclusions.

The " $P$ pulmonale" pattern, described by Winternitz (1935) in chronic pulmonary disease of tall pointed $\mathbf{P}$ waves in lead II and by later workers in right chest leads, has been reported by numerous authors with great variation in results and interpretation. Some (Wood, 1948; Kilpatrick, 1951) found a high incidence (60-85\%), and others (Fox and Kremer, 1943; Lepeschkin 1951) much lower (5-30\%). Recently Zukerman et al. (1948) and Hecht and Woodbury (1950) have postulated that it is merely a factor of the electrical position of the heart. When it was possible to discern the exact type of cases reported, it was evident that the standard of case selection and severity was not constant. In our series, we endeavoured to separate cases with severe emphysema with respiratory difficulty from similar cases who were in actual right heart failure. We also studied a small group of primary pulmonary hypertension. In the first two groups we 
found few changes from normal, except a slightly higher incidence of pointed waves, 40 per cent against the normal of 22 per cent. However, it was interesting that in two cases of emphysema in failure that showed definite clinical evidence of pulmonary hypertension, there were tall pointed or diphasic waves in CR1, thus showing right atrial abnormality.

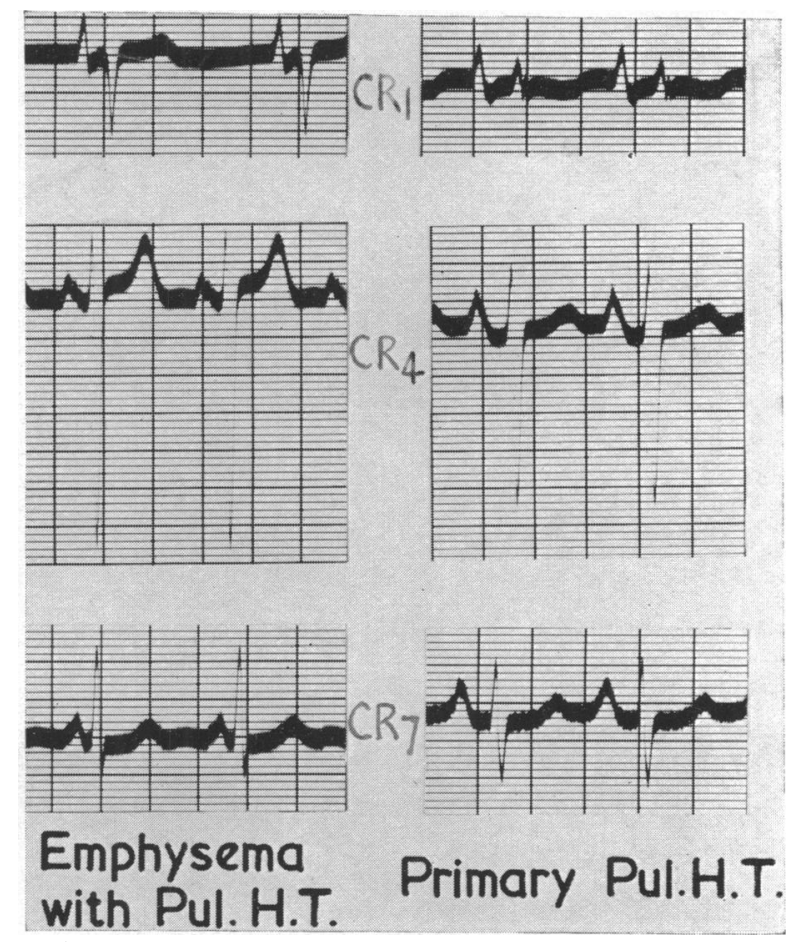

FIG. 4.-Tall diphasic $P$ waves in CR1 in emphysema in heart failure and with pulmonary hypertension $(A)$, and in primary pulmonary hypertension (B), denoting right atrial abnormality.

In primary pulmonary hypertension we found a typical pattern of abnormal right atrial activity with tall pointed waves in most leads and noticeably in CR1. At times a diphasic wave of large amplitude occurred (Fig. 4). The correlation of the " $P$ pulmonale" pattern with post-mortem studies has not always been consistent and has been reported in varying degrees by (Scott and Garvin, 1941; Katz et al., 1942; Szekely, 1944). As has been shown (Winternitz, 1935; Katz et al., 1942; Harkavy and Romanoff, 1942; Hajos, 1948) the "P pulmonale" pattern has decreased or disappeared in some cases of asthma following a period of marked respiratory distress. Though the number of cases is not significant in this group, it is suggested that the common factor in chronic pulmonary disease that gives the abnormal right atrial pattern is transient or persistent pulmonary hypertension. This may be one of the factors accounting for the variability of previous reports.

Many authors (Wood and Selzer, 1939; Allanby and Campbell, 1949; Woods, 1952) have noted tall pointed $\mathbf{P}$ waves in congenital heart disease, especially in pulmonary stenosis. Recently, Paul et al., (1951) analysed 96 cases of congenital heart disease proved by catheterization, operation, or post mortem. They found pulmonary stenosis, either alone or associated with other conditions such as atrial septal defect or as part of the tetralogy of Fallot, to be the main cause of abnormal $\mathbf{P}$ waves. They were tall and pointed and seen best in right chest leads. They also found similar waves in Ebstein's disease but found tall broad waves in right chest leads in tricuspid atresia. Campbell and Reynolds (1952) have shown the difference in the direction of the P wave 
in dextrocardia and lævocardia. In our series, pulmonary stenosis was the only group, as a whole, to show any significant abnormalities. Tall pointed waves were more common in all leads and had the greatest average height of the series. These occurred, as expected, most often in CR1 and CR4 (Fig. 5). Seventy per cent of the group thus showed right atrial abnormality. Two cases of atrial septal defect and one of ventricular septal defect showed evidence of right atrial abnormality, and it was interesting to note that these cases were the only ones in their group clinically to show marked pulmonary hypertension.

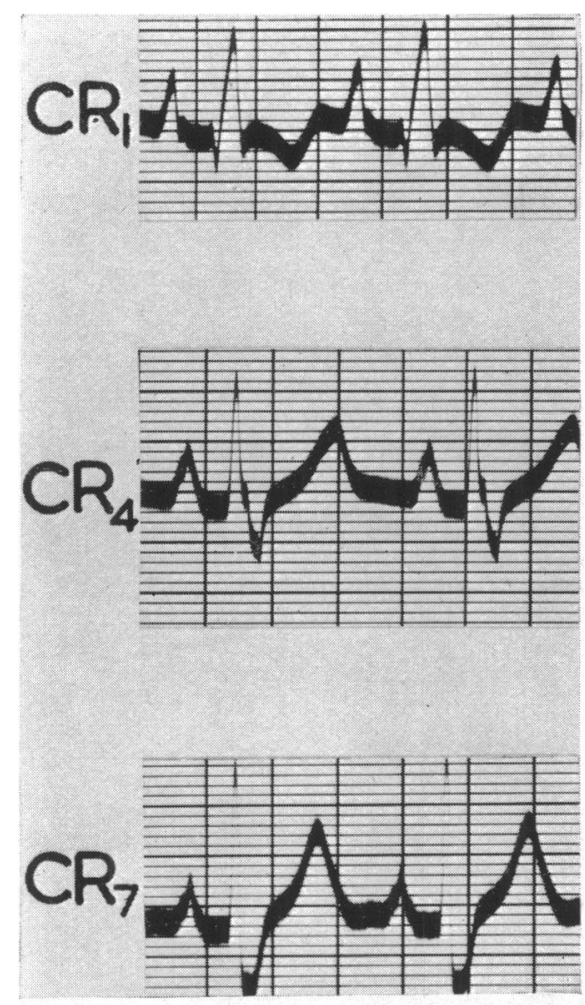

FIG. 5.-Pulmonary stenosis. Tall pointed waves in CR1 showing right atrial abnormality.

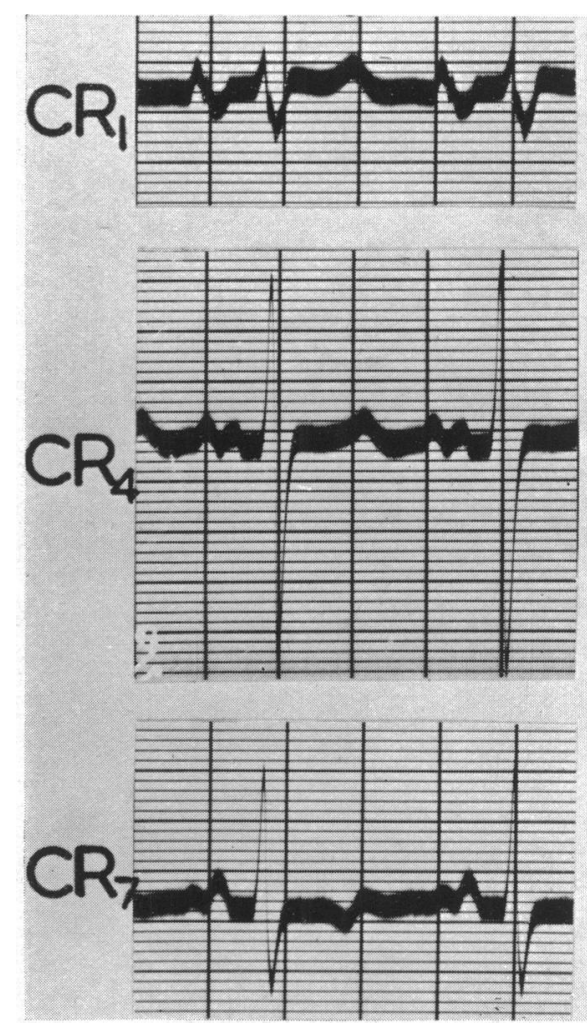

Fig. 6.-Constrictive pericarditis. Prolonged peak interval of bifid waves as evidence of left atrial abnormality.

Abnormal bifid P waves have been noted in constrictive pericarditis by Evans (1945) and more recently by Chamblis et al. (1951). We found this to be a rather characteristic pattern as well, with a marked increase in the total bifid waves and average peak interval. An abnormal bifid $\mathbf{P}$ wave was present in 11 of the 13 cases. Though the left atrium showed abnormality in three-fourths of these, a small but definite number showed evidence of both right and left atrial disturbances, which is not unexpected considering the nature of the disease (Fig. 6).

\section{SUMMARY}

Generally, in the past, only empirical facts of $\mathbf{P}$ wave abnormality in the standard electrocardiograms have been recorded. Recent studies, including direct recordings, have shown a purer type of wave and asynchronization of atrial response, giving a better conception of atrial activity. With this information in mind, the purpose of this investigation was to record the pattern in health 
and in heart disease to see if single and bi-atrial activity and abnormality could be noted in the standard electrocardiogram.

A standard of normal was established from a series of healthy cases. Cases of heart disease in which a strain on one or both atria was known were selected and divided as to ætiology and severity. From an evaluation of these cases, chest leads were found to be best for the study of bi-atrial activity. Pointed, diphasic, and the three types of bifid waves (which give the best representation of direct recording and asynchronization) produced the most information. The analysis of bifid waves was essential. Bifid waves of the first peak type and diphasic waves occurred exclusively in right chest leads. Bifid waves of the second peak type occurred exclusively in left chest leads. A prolonged peak interval (greater than 0.04 sec.) occurred in all records of cases showing abnormality of the left atrium and never occurred in cases showing only abnormality of the right atrium. The occurrence of convex, impure bifid, isoelectric, and negative waves was of little value.

From this information and the correlation of the incidence of these waves with the disease groups, as well as from the standard of normal, criteria were established for separate and combined atrial abnormality and the terms of right atrial abnormality and left atrial abnormality proposed. Right atrial abnormality was present in 70 per cent of the cases of pulmonary stenosis, in all of the cases of primary pulmonary hypertension, and in cases of pulmonary hypertension occurring in other diseases, namely, atrial septal defect, ventricular septal defect, and emphysema in failure. Left atrial abnormality was present in half of the mild cases and all of the more severe cases of mitral stenosis, and in 85 per cent of the cases of constrictive pericarditis. Combined atrial abnormality was present in half of the moderate and severe mitral stenosis cases, especially in those with pulmonary hypertension and those with large hearts, and in 23 per cent of cases of constrictive pericarditis.

\section{CONCLUSIONS}

Single or combined atrial abnormality can be diagnosed in the standard electrocardiograms. Right atrial abnormality is present when the P wave in CR1 is tall (more than $2.5 \mathrm{~mm}$.) and is diphasic, pointed, or bifid of the first peak type. Left atrial abnormality is present when a tall (more than $3.0 \mathrm{~mm}$.) bifid P wave of the second peak type occurs in CR4 or CR7, or an abnormally long peak interval occurs in a bifid wave in any lead regardless of voltage. Combined atrial abnormality is suggested where a $\mathbf{P}$ wave deformity characteristic of both right and left is present.

We would like to thank Dr. William Evans for advice and help in the preparation of this paper.

\section{REFERENCES}

Allanby, K. O., and Campbell, M. (1949). Guy's Hosp. Rep., 98, 18.

Ashman, R., and Hull, E. (1937). Essentials of Electrocardiography. 1st ed. New York.

Bachmann, G. (1916). Amer. J. of Physiol., 41, 209.

Baker, C., Brock, R. C., Campbell, M., and Suzman, S. (1949). Brit. Heart J., 11, 170.

Berliner, K., and Master, A. M. (1938). Arch. intern. Med., 61, 39.

Campbell, M., and Kauntze, R. (1953). Brit. Heart J., 15, 179.

$\longrightarrow$, and Reynolds, G. (1952). Brit. Heart J., 14, 481.

Chamblis, J. R., Jaruszewski, E. J., Brofman, B. L., Martin, J. F., and Feil, H. (1951). Circulation, 4, 816.

Deeds, D., and Barnes, A. R. (1940). Amer. Heart J., 20, 261.

Einthoven, W. (1906). Arch. int. Physiol., 4, 132.

Eisenberg, G., and Gibson, S. (1941). J. Pediat., 19, 452.

Endelberg, C. D. (1951). Amer. Heart J., 41, 832.

Evans, W. (1945). Brit. Heart J., 7, 215.

- (1948). Cardiology. 1st ed. London.

- , and Jackson, F. (1952). Brit. Heart J., 14, 53.

Fox, T. T., and Kremer, H. S. (1943). Amer. Rev. Tuberc., 47, 135.

Fredericq, L. (1906). Arch. int. Physiol., 4, 57.

Goldberger, E. (1953). Unipolar Lead Electrocardiography and Vectorcardiography. 3rd ed. London.

Graybiel, A., McFarland, R. A., Gates, D. C., and Webster, F. A. (1944). Amer. Heart J., $27,524$. 
Groedel, F. M., and Borchardt, P. R. (1948). Direct Electrocardiography of the Human Heart. Brooklyn Medical Press Inc.

Hajos, M. K. (1948). Ann. Allergy, 6, 655.

Harkavy, J., and Romanoff, A. (1942). Amer. Heart J., 23, 692.

Hecht, H. and Woodbury, L. A. (1950). Circulation, 2, 37. , (1943). Proc. cent. Soc. clin. Res., 16, 56.

Katz, L. N. (1946). Electrocardiography. 2nd ed. Chicago.

-, Godman, A. M., Langendorf, R., Kaplan, L. G., and Killian, S. T. (1942). Amer. Heart J., $24,627$.

Kilpatrick, J. A. (1951). Brit. Heart J., 13, 309.

Kisch, B., Groedel, F. M., and Borchardt, P. R. (1947). Exp. Med. Surg., 5, 426.

Leatham, A. (1950). Brit. Heart J., 12, 213.

Lepeschkin, E. (1951). Modern Electrocardiography, Vol. 1. 1st ed. London.

Levine, H. D., Hellems, H. K., Wittenborg, M. H., and Dexter, L. (1949). Amer. Heart J., 37, 46.

Lewis, T., (1925). The Mechanism and Graphic Registration of the Heart Beat. 2nd ed. Shaw \& Sons, London. and Gilder, M. D. (1912). Phil. Trans., 202B, 351.

Luisada, A. (1940). J. Lab. Clin. Med., 25, 1146.

Macleod, A. G., Wilson, F. N., and Barker, P. S. (1930). Proc. Soc. exp. Biol., 27, 586.

Myers, G. B., Klein, H. A., Stofer, B. E., and Hiratzka, T. (1947). Amer. Heart J., 34, 785.

Oblath, R., and Karpman, A. B. (1951). Amer. Heart J., 41, 369.

Pardee, H. E. (1941). Clinical Aspects of the Electrocardiogram. 4th ed. New York.

Paul, O., Myers, G. S., and Campbell, J. A. (1951). Circulation, 3, 564.

Rasmussen, H., and Nyhus, G. (1948). Acta med. scand., 129, 446.

Reynolds, G. (1953). Brit. Heart J., 15, 250.

Scott, R. W., and Garvin, C. F. (1941). Amer. Heart J., 22, 56.

Shipley, R. A., and Hallaran, W. R. (1936). Amer. Heart J., 11, 325.

Sorsky, E., and Wood, P. (1937). Amer. Heart J., 13, 183.

Stewart, C. B., and Manning, G. W. (1944). Amer. Heart J., 27, 502.

Szekely, P. (1944). Brit. Heart J., 6, 238.

Taussig, H. B. (1947). Congenital Malformations of the Heart. N. Y. Commonwealth Fund.

Trounce, J. R. (1952). Brit. Heart J., 14, 185.

Wenger, R., and Hofmann-Credner, D. (1952). Circulation, 5, 870.

White, B. V., Parker, R. C., Jr., and Master, A. M. (1944). Arch. intern. Med., 74, 95.

Wilson, F. N. (1943). Cyclopedia of Med. Surg., a Special, 3, 799.

Winternitz, M. (1935). Med. Klin., 31, 1575.

Wood, P. (1948). Brit. Heart J., 10, 87.

, and Selzer, A. (1939). Brit. Heart J., 1, 49, and 1, 81.

Woods, A. (1952). Brit. Heart J., 14, 193.

Zukerman, R., Rodriguez, M. I., Sode-Pallares, D., and Bisteni, A. (1948). Amer. Heart J., 40, 805. 